\title{
A reciprocal relationship - an opportunity and a solution for a meaningful daily life in home care - the older person's perspective
}

\author{
Annica Kihlgren ,' Karin Blomberg, Inger James \\ School of Health and Medical Sciences, Örebro University, Örebro, Sweden
}

Received: May 13, 2014

Accepted: November 2, 2014 Online Published: December 1, 2014

DOI: $10.5430 /$ cns.v3n1p71

URL: http://dx.doi.org/10.5430/cns.v3n1p71

\begin{abstract}
Background: Shortcomings in elderly care have been reported in many parts of the world, including Sweden. National guidelines for elderly care have been introduced in Sweden, which contain core values and local guarantees of dignity. These highlight the need for dignity and well-being and organizing the older person's daily life so that she/he perceives it as meaningful. Therefore, the aim of the present study was to explore opportunities, obstacles and search for solutions as described by the older person in order to create a meaningful daily life.

Methods: The design is based on the underpinning view of seeing the older persons as narrators of their own stories and interpreters of their own lives. Participatory Appreciative Action Reflection (PAAR) was used when collecting the data. Fifteen older persons participated, and repeated interviews were carried out as reflective conversations, in total 30 interviews. The older persons provided their analyses and reflections on what had been said regarding a meaningful daily life. Finally, an analysis of the data was done, based on interpretative description, and an inductive approach built on the key axioms of naturalistic inquiry.

Results: The older persons' experiences and knowledge of opportunities, obstacles and solutions to a meaningful daily life can be summarized into four themes: (1) to live as usual, (2) collaboration with the staff, (3) the relationship carries everyday life, and (4) belonging to something. In the discussion, we choose to further develop these four themes by using Buber's philosophy of dialogue.

Conclusions: An opportunity and a solution for meaningful daily life for the older person were seen in the relationship to oneself, to staff, to others, and the family. The reciprocal relationship, which occurred in the interaction between the staff and the older person, was the opportunity and solution for a meaningful daily life. It was the ongoing conversation between the older person and the staff who became "the glue" and formed the relationship. If the staff could support the older persons to maintain their habits and routines, these were solutions for creating a meaningful daily life. A meaningful daily life could be obtained in an I-Thou relation in a shared everyday life, where the relationship and the continuing dialogue becomes the power of balance. The relationship is also relevant for the staff and in line with Buber's thoughts on how we are shaped by humans in the encounter with others.
\end{abstract}

Key Words: Action research, Home care, I-Thou relation, Meaningful daily life, Reciprocal relationship

\section{Introduction}

The World Health Organization (WHO) recognizes that we are globally facing a challenge in terms of the elderly pop- ulation's health with several health problems at the same time. Several of the very old cannot live independently which can result in an increased need for long-term care such as home care or residential care in a nursing home. ${ }^{[1]}$

\footnotetext{
* Correspondence: Annica Kihlgren; Email: annica.kihlgren@oru.se; Address: School of Health and Medical Sciences, Örebro University, SE 70182 Örebro, Sweden.
} 
Increased costs for the society, as well as the older persons' preference to age living at home, have led to a shift from nursing home care to home care. ${ }^{[2,3]}$

More and more older persons want to remain at home, socalled aging in place, and this is something that is assumed to increase. ${ }^{[4]}$ What is meant by home-care systems differs both between and within countries. ${ }^{[5]}$ However a home, or ordinary housing, can be described as a space that belongs to the person who lives there and who has the right to close the door to others. Health care staffs enter this space with permission and can be viewed as guests in the older person's home. The home stands for values such as identity, dignity and privacy ${ }^{[6]}$ This could mean that the care provided by the staff is expected to contain an approach in which these values are respected. However, deficiencies from many countries within home care such as maltreatment, which can lead to serious physical injuries and long-term psychological consequences, are reported ${ }^{[1]}$ Home care is often criticized for it being fragmented. ${ }^{[7]}$ The home care staff's lack of time and changing schedules create anxiety and uncertainty in the older person's daily life. ${ }^{[8]}$

Several aspects influenced good care in home care; the relationship with the staff is of great importance. ${ }^{[9,10]}$ Another aspect is to feel secure when receiving care; competence and skills of the health care staff are conditions of care. ${ }^{[8]}$ Further aspects that are described are adaptation and acceptance of becoming dependent. ${ }^{[11,12]}$ However, the aim with home care is to assist the older persons to live independently in their homes. ${ }^{[4]}$

Several reports in Sweden show that the older person's participation in and the opportunity to influence the content of the care are limited. ${ }^{[13]}$ Older people's preferences and habits in daily life are not fulfilled, ${ }^{[14,15]}$ and working routines take priority over the needs of the older persons. ${ }^{[14]}$ Due to the shortcomings that have been noted in the health care and social services, the government in Sweden has introduced national guidelines for elderly care, which are core values and local guarantees of dignity. The guidelines highlight the need for dignity, well-being and organizing the older person's daily life so it is perceived as meaningful. ${ }^{[13]}$ Perceived meaning-in-life for older persons within home care is sparingly studied, but studies from nursing home care show that it is significantly associated with the quality of life dimensions: physical, emotional, social, and functional well-being. ${ }^{[16]}$ However, it can be difficult for older persons to find a meaningful daily life ${ }^{[16]}$ in elderly care, due to the shortcomings that have been reported in many parts of the world. ${ }^{[13]}$

When national guidelines are introduced, the guidelines may be designed in a comprehensive plan of activities known as the "top down" perspective, where the government decided that each municipality should formulate its own core values and local guarantees of dignity. How the mu- nicipalities apply the core values and local guarantees, how they are supposed to work, and how the organizations have the opportunity to develop by themselves are critical. ${ }^{[13]}$

This study is a part of a larger interdisciplinary action research project in collaboration between one municipality and a university in central Sweden. The aim was to develop an understanding of a meaningful daily life for older persons in need of municipality care. Another aim was to develop core values and local guarantees of dignity in the municipality. Several stakeholders, older people, their relatives, staff and managers were included in the study. ${ }^{[17]}$ This study focuses on the older persons living in ordinary housing with home care service. The aim was to explore opportunities, obstacles and search for solutions as described by the older person in order to create a meaningful daily life.

\section{Methods}

\subsection{Design}

In this study we invited older persons together with us to cocreate knowledge about what a meaningful daily life means, when municipal home care service is needed. The design is based on the underpinning view of seeing the older persons as narrators of their own stories and interpreters of their own lives. Additionally, we also strove hard to break down barriers between our "expert knowledge" and the older persons "lay knowledge". The Participatory Appreciative Action Reflection (PAAR) approach, which is based on action research, was used when collecting data. This research has its roots in participation in thought and action with the participants. An appreciative perspective was applied and we tried to identify what worked well in practice. What distinguishes PAAR from other action research is the appreciative intelligence, which means to take advantage of people's ability to be innovative and creative. If only problems are diagnosed within an organization, it takes the energy from the system. The intention was not to overlook problems and deficiencies but to adopt a creative yet critical stance and seek solutions together with the participants. ${ }^{[17,18]}$

\subsection{Sample}

Older persons 65 years and over were strategically selected $^{[19]}$ from three different home care units within a municipality in Sweden. One of the units had received favourable ratings, one had received average ratings, and one had received the lowest ratings in a recent user survey. ${ }^{[20]}$ Oral and written information of the study were given to the older persons by the manager of the home care unit. The first five older persons from each home care unit who agreed to participate were included in the study. The researcher took contact with the older persons after they had signed the written consent. Altogether, fifteen older persons participated, ten women and five men and their ages was between 83 to 95 years ( $\mathrm{m}=87$ years). The help and 
support that was needed to get everyday functioning varied. There were older persons who had only help with delivering food and/or cleaning. Others needed to have extensive health care, for example, visits by home care five times a day. It could also be that someone had had extensive need for support and assistance during an illness, but after they had become better, the aid was reduced.

\subsection{Ethical consideration}

Permission to interview the older persons with home care was given by the Regional Ethics Committee (2011/009). The older persons were not regarded as dependent on the interviewer in any way, and they could decline participation in the study at any time without giving a reason. The researcher saw it as important to ask if the older person wanted to end the participation in the project, to be sensitive and observe the person's body language. If they in any way expressed or signalled unease or discomfort with the interviews, we would have cancelled them. No interviews were cancelled because of unease or discomfort.

\subsection{Data collection}

Repeated interviews i.e. 2 interviews per participant were carried out as reflective conversations like open interviews. $^{[21]}$ The reflective conversations were flexible in nature, lasted from half an hour to one and one-half hours. It was important that the time between the interviews was not too long due to the risk that the participants had forgotten the prior conversation. The interviews were carried out by two research assistants and one of the researchers; the interviews also were audio recorded. The time and place for the interviews were chosen by the older persons and were carried out in the older person's home. To co-create knowledge, an appreciative intent and confirmation through interaction was sought for in each interview. ${ }^{[18]}$ Open reflective questions were asked: How does daily life looked like for the older person, and how could a meaningful daily life be developed. Positive issues for reflection were raised with regard to what factors might be positive in everyday life at this particular time. Follow up questions that were asked: How are these potential positives achieved? What factors are less favourable, and what obstacles may be found in everyday life? Do you have any suggestions as to how these obstacles can be avoided or resolved? The interviews were transcribed verbatim by a secretary and were documented chronologically and compiled on a continuing basis. In a next step, the compilations were taken back to the older persons who, together with the researcher, provided their analyses and reflections on the content of what had been said regarding a meaningful daily life as an older person in a need of home care. ${ }^{[17]}$

\subsection{Data analysis}

The analysis was based on interpretative description, ${ }^{[22]}$ an inductive approach built on the key axioms of naturalistic inquiry. ${ }^{[23]}$ We initially read the transcripts repeatedly to obtain a sense of the data as a whole. Similarities and differences were searched for, as well as for the older persons' descriptions of their experiences. We asked questions to the data: How do the older persons describe obstacles and opportunities and solutions for developing a meaningful daily life? Do the older persons describe it differently? Their assumptions and assertions were also compared in the data in order to find similarities and differences in the text. An overall dimension and four themes were identified across the data with subthemes describing similarities and differences. All authors discussed and validated the preliminary findings. Quotations are presented below to illustrate the findings, having been translated from Swedish to English by an authorized translator. Hesitations and unnecessary words are indicated by (...), and square brackets [ ] indicate comments from the authors.

\section{Results}

The older persons' experience and knowledge of opportunities for and obstacles to a meaningful daily life can be summarized into four themes. The themes describe how a meaningful daily life can be created by highlighting opportunities, obstacles and solutions.

\subsection{Live as usual}

An opportunity to develop a meaningful daily life was to live as usual. Obstacles to this were to feel demands related to not being mobile. The reduced mobility, in turn, meant that the older persons became excluded from their everyday context. A solution to reach meaningfulness was to try and maintain daily life with its routines and habits.

\subsubsection{Not being mobile/feeling demands}

The older persons described how the body became an obstacle in the daily life. They found it difficult to move around and do what they were used to. It became burdensome to not be able to do things that previously had gone easily, to bend down and pick up something from the floor. One older person said: "Yes there are so many demands in everyday life. So if you're not in that situation you don't have the imagination to figure it out".

\subsubsection{Being excluded}

The limited mobility could lead to anxiety and fear that the everyday life would not work at home. The older persons could be worried about falling, and for some it became difficult to always remember to take the walker and keep it with them. Further, it could also be a matter of concern that they would not survive the night without alarming. It became a demand to carry out everyday work; it could require a great deal of planning, which in turn became energy-consuming. 
Limited mobility made it more difficult to participate in social situations, for example, excursions.

"Firstly, I find it difficult to get off and on a bus as it is virtually impossible to climb up. I've been going before, but then they've got to carry me".

\subsubsection{Sustaining daily life}

A solution for a meaningful daily life was that it worked as usual as it always had. The older persons had hopes of being able to live at home, in ordinary housing, as long as possible and to manage with the help and support that they received from the home care service. It gave them joy to be able to manage with certain daily tasks, for example, to cook one's food, to dust, to be able to go out by oneself and take a walk or to take one's own medicine in the dosage unit. It was important to be able to handle what you've always done and taken for granted, as to continue to take care of the personal hygiene for oneself. One older person said: “... after I have showered so I try to roll my hair on a bit myself - have always done this".

If the older person had to have a great deal of help, it was also useful to be able to do what he/she still could do, such as to read the newspaper for her/himself.

"To be able to read the newspaper, it feels good, and sometimes it is possible to solve the crossword puzzle, it feels good".

It could also be that they had received such adequate help and support in daily life from the municipality, so that everyday life from being quite isolated and dull had resulted in the person becoming mobile and the daily life more meaningful.

\subsubsection{Getting/enjoying meals}

The taste of the food and how it was served was an opportunity and a solution for a meaningful daily life. For many of the older persons, meals were something they looked forward to. The food could often be cooked well, but it could also be described as tasteless.

"It is a good thing. Clearly, sometimes it may be that you don't like it, of course, if it is a little poorly seasoned, but it can be done by yourself. There may be people who think there are too many spices".

One obstacle to a tasty meal was that the food was delivered cold and needed to be heated. If the food was heated on high heat and for a long time, it was the almost inedible. A common complaint was that the potatoes were rarely properly cooked. The older people wanted freshly boiled potatoes: "I have cold food and the potatoes are not cooked. I must cut the potatoes into slices; mashed potatoes are good. Food is important for a good day".

\subsection{Collaboration with the staff}

An opportunity to develop a meaningful daily life was to collaborate with the staff. Obstacles to this were that the older persons and the staff did not know each other, which created anxiety and fear. The older persons also found that the staff lacked medical and practical knowledge. In these encounters, it became the older person who had to instruct the staff how to perform the care activities/actions. Opportunities for collaboration and a solution for a meaningful daily life was that the older persons created reciprocity to the staff.

\subsubsection{Not knowing the staff}

An obstacle was new staff members all the time. The staff and the older persons did not get to know each other. This could mean that staff could not perform the care in the way that the older persons wanted, meaning that the older persons had to be alert and able to explain and instruct the staff as to what they wanted done. This took energy. It became an obstacle to be afraid and stressed because an unknown staff member could not properly perform the care.

"The assistance varies, there is no continuity. It leads to mistakes and then I have to know what they should do. You get to start over and over again. If it is too often, I get unsure and then get it wrong. You're afraid of those who come rarely".

It was not just that the staff would perform tasks. For the older persons, it meant to surrender to someone else, and then it was important to know the staff in order to be able to rely on them.

"It is very important that the staff knows what to do. It's about leaving oneself to another human being. When the person you trust comes, you can live for that and wish she will come next time. Then the day will be fine".

\subsubsection{The staff is not knowledgeable}

An opportunity for a meaningful daily life was if the staff that came to give help and support had knowledge of how to perform the care. An obstacle arises when the older persons experienced that the staff did not have enough medical or practical knowledge. "... I alerted several times during my stroke. They said it was nothing. The personnel's medical knowledge is important".

\subsubsection{Creating reciprocity}

Creating reciprocity was a solution for a meaningful daily life and made sense and joy in the everyday life. Reciprocity in the encounter between the older persons and the staff made the atmosphere between them better. The older person tried to be happy, and it was positive if the staff members were happy and used humour during the time they were in the older person's home and performed care. 
"Yes, it is pleasant when the personnel are nice to me, and I'm nice to them".

An obstacle was shown when staff's stress appeared in their body language or was heard in the tone of their voice. The staff could have difficulty keeping up with what they were doing; any other older person could have fallen, so the staff had to hurry to get there. The older persons understood this: the next time it could be their turn to alarm because they had fallen.

Furthermore, they understood and could familiarize themselves with the staff's situation if they were stressed and tired; they adapted to this. The older persons received help by the staff and wanted, in return, to help them.

“Yes, but it's noticeable. And a little irritated they can be at times if they have or if they are out in the final minutes so to say. If they become stressed. There is always someone who has called and wants help. I can't say anything because I have called myself when I could not get up".

\subsection{The relationship carries everyday life}

An opportunity and solution to develop a meaningful daily life was to have a relationship with the staff. It was important that the staff saw and listened to the older person, and that the staff gave engagement and "love". It was the ongoing conversation which became "the glue" and formed the relationship.

\subsubsection{Getting to know each other}

The most significant opportunity for the older persons was that she or he and the staff knew each other, which were prerequisites for being able to create a relationship. This facilitated also the collaboration between the older person and the staff.

“... now I've got to switch group [home care group] and it is sad because now we have gotten to know each other. It's the relationship that is most important for a good day. It is sad and the new ones do what they can. So, it isn't that, but before I get to know them ...”.

The relation with the staff was important for a meaningful daily life, and the older person said that the relationship would be a close relationship like being a friend. A relationship was one in which they talked with each other about everyday life, the weather, important issues in the community, and what happened in the world was important. The older person wanted to be seen and listened to, i.e., so that the staff adapted to them.

To make the day meaningful for the older person, it was an opportunity when the staff adapted to the older person, knowing who the older person was, what characteristics and personality he or she had, and in what situation she or he was in.

Published by Sciedu Press
"One's behaviour may be a bit different depending on the person. One can say things that are not offensive, but it can be taken very unpleasantly. Then, it depends on whether the recipient is extremely shock sensitive, so to speak, or not".

Interviewer: The staffs often say that they often feel others' feelings. What is meant by it? "They probably try to get themselves into the others' personality and feel instinctively".

An opportunity and a solution for the older persons were to get noticed by the staff, which gave them praise if they had done something well. To still be able to manage things in everyday life or to be intellectually stimulated gave a personal satisfaction and meaning. The older persons did not want to feel frail. The help and support the older person received in his or her home should be based on the older person's condition. The older persons wanted to be able to decide what to do in their own homes; most important for the staff were to be able to stop and listen: what the older persons wanted in their everyday life, if the care was performed as the older person wished, and if this would be opportunities and solutions for a meaningful daily life.

"If the staff can listen to what I have to say, then there will be no problem, then it will be fine.

\subsubsection{Having engagement}

The engagement among the staff could be an opportunity. The older persons told the staff that they needed to be involved, to be a part of the situation, to be interested in the persons they cared for as well as to be accommodating to the older person as she or he wanted to be met: "A person who comes and is there with the whole of her/his being. This is not always a given, but is pleasant for us elderly."

It was important that the staff performed the care with accuracy and engagement, not just performing with routine tasks.

"Staff who knows how to use their hands .... Then it becomes not a mechanical scrubbing."

\subsubsection{Giving love}

It could be difficult to describe the engagement the staff used in the performance of care. An older person described this as love.

Interviewer: "What is the difference between someone who really takes care of you, creating meaning, and those that do not? What's the difference?"

The older person: "It's not possible to describe, is it? Because so much love that you get ...”.

There were older persons who had experience of staff engagement that could be linked to body contact. A pat on the shoulder or a hug could give intimacy and warmth and be very significant. 
If there was a continuing dialogue in the daily life where the staffs were interested in what the older person had said, it makes the day meaningful. The staff should listen, be in the conversation and in the situation, and show this by asking follow-up questions. Together they, the older person and the staff, could share experiences and continue to talk about what they previously had talked about when they last met.

\subsection{Belonging to something}

One opportunity or solution to develop a meaningful daily life was to have a sense of belonging. Obstacles to this were if there was no room for the soul in the everyday life or if the older person felt alone. One opportunity was if there was time for conversation. Furthermore, to get out, feel free and feel close to others such as friends and relatives were important activities.

\subsubsection{Make way for the soul}

Some of the older persons expressed that the body was met with physical exercise, but the soul was forgotten in elderly care, which was an obstacle for a meaningful daily life.

"There was training; we had a physical therapist but we also needed a psychologist. We needed both for the body and mind. Really, we should meet with a psychologist”.

One older person described it as horrible that older persons paid for their care but there was no time for conversation. The older person had worked hard during his/her whole life and should not be punished due to lack of staff. However, the staff member was not always suitable for conversation. It could be that some staff did it well while others did not, but conversation was seen from the older person's perspective as a solution for a meaningful daily life.

"Conversations with one another are an important part in health and social care; conversations require natural ability and some are not capable of this".

\subsubsection{Feeling lonely}

One obstacle to a meaningful daily life for the older persons was the feelings of loneliness. Their relatives could be busy with work and other things in everyday life and did not have time for anything else. They could also be sick and/or older relatives could also have died.

An older person described it as feeling isolated and abandoned, and they find themselves on a deserted island. Another described it as the light goes out the day when you turn 65 and are forced to retired.

\subsubsection{Making time for existential conversations}

It was an opportunity for a meaningful daily life if the older person within elderly care was given time for conversation. The staff needed life experiences, to be human and to be able to understand the older persons, which created meaning. The staff needed to understand that the older persons could have experiences of difficulties and sorrow in their lives. Conversation about sorrow and existential life issues were important for the older person.

"Yes, what I like best is if you can sit and talk because X has just died, so I feel very alone. So I think it is nice to get things off one's chest, so to say".

\subsubsection{Coming outside and feeling free}

A meaningful daily life could also be described as something happening out of the ordinary or just as a disruption of everyday life. To take the transportation service and go up town and look at people could be meaningful. There could also be some music entertainment in a nursing home nearby as they in ordinary housing, with home care, had the opportunity to visit.

"to be able to go over to ... the old peoples' home when they have something going on, music or so, then it will be fine".

\subsubsection{Being close to others}

To read and look at the TV could also give a meaning. The older persons stressed the television's significance. It could be company, something to do if you wake up in the middle of the night and could not sleep. It could also offer intellectual stimulation with various quiz programmes and popular science programmes. There were also those who complained if the scheduling was poor when it turned to a younger audience.

Nature programmes are the best I know. I really like animals. I have had three cats.

There were also older persons who said that being alone was fine: They did not need so much company.

An opportunity for a meaningful daily life was to meet friends who were still living. There were older persons who had friends and acquaintances for many years that they were close to, which gave them a sense of meaning. There was also a longing to meet new friends whom they had chosen on their own.

"It's not something arranged one wants to happen, but something that occurs intuitively along the way”.

There were also other older persons who described having lost their partner (become a widow or widower). If the daily life should be really meaningful, they wanted to meet a new partner. Not necessarily to move together, but someone they could be themselves with and someone to talk with and share thoughts. Maybe enjoy a meal together, go to the movies or the theatre.

Relatives have great significance for a meaningful daily life. To be close to children and grandchildren was a joy. However, the relationship with relatives looked differently 
among the older persons. There were relatives who did not have very much opportunity to come and visit/see the older person, but they did the best they could.

Because I cannot always call the kids and say: "Come here now because I don't feel well or so. No. Although, my children are very good at visiting and phoning me to say hi”.

Furthermore, there were relatives who did the shopping, cleaning and laundry. While others came and provided support, so the older person could get out. It could also be that the older person went to relatives via the transport service.

\section{Discussion}

The older persons created their own meaningful daily life by striving to live as normally as usual in everyday life and maintaining their routines and habits. These can be seen as sustaining the self. There was a struggle between handling the increased demands and doing everyday activities. The older person created a reciprocity and collaboration with the staff for a meaningful daily life. The ongoing dialogue, between the older person and the staff, became "the glue". Further, for a meaningful daily life it was important to have a sense of belonging, a sense of closeness and togetherness, as well as keeping one's earlier relations but also establishing new ones.

The results show clearly that a meaningful daily life for the older persons is constituted by relationships, which created opportunities and solutions for a meaningful day. We chose to discuss our result using Buber's philosophy of dialogue where the interpersonal relationship is central. Buber makes a difference between a relationship constituted of an I-Thou relation and an I-It relationship. A relationship of I-Thou is characterized by facing a man as a subject, a Thou. ${ }^{[24,25]} \mathrm{A}$ relationship constituted as an I-It relationship is characterized by someone who is considered as an object. We can experience other people by deciding someone's height and weight, which may mean that we dissect someone and start deciding as to someone's characteristics/qualities. This may mean that we consider someone as a thing, an I-It relationship. ${ }^{[24]}$

In order to fully understand the meaning of I-Thou and IIt, we must assume that the world is twofold. Is there an I it must be a thou, if opportunities exist there will be obstacles. However the everyday life is more complex than that, but Buber's philosophy that clearly makes a difference between I-Thou and I-It, is in line with this study on obstacles and opportunities. Buber's theory can serve as a theoretical and analytical tool in order to deepen our understanding of how solutions for a meaningful daily life in homecare can be created.

\subsection{The relationship to oneself}

To live as usual was an opportunity and a solution for a meaningful daily life for older persons living in ordinary housing, but reduced mobility that triggered a need for help could create an obstacle. Mobility is one of the most important functions in order to maintain independence and to participate in various forms of activities with others. ${ }^{[26]}$ An increased dependency affects the self-image. ${ }^{[27]}$ The older persons in the present study struggled to do their everyday work, and they were scared and worried about falling. The Dollard, Barton, Newbury, and Turnbull ${ }^{[28]}$ study revealed that falling was a threat to an older person's identity. The older persons did not want to fall or to seem like someone who could fall. This is related to how we want to present ourselves to others. ${ }^{[29]}$

It was important to remain at home for the older persons; a home can stand for meaning, privacy, security and identity. ${ }^{[6]}$ The home is a way to keep the past alive and gives a sense of belonging and strength of the self that may provide a hedge against threatening changes in one's life. ${ }^{[6,30]}$

The older persons had experienced the body as an obstacle and that he/she became excluded from their everyday context. Everyday life can be experienced through the body, in the form of pain, through the care of the body, and through the body's decreased physical and mental functions. ${ }^{[31]}$ These experiences can result in that the body is experienced as an I-It, an object. This can be described as the older person had an I-It relation to their body. They were striving to sustain habits and routines, i.e., the lifestyles where they can live as usual which can be a way to maintain a relationship to oneself, a self-identity ${ }^{[32]}$ and a I-Thou relationship. ${ }^{[25]}$

\subsection{Reciprocity and collaboration between the older person and the staff}

Obstacles for a meaningful daily life were that the staff and the older persons did not know each other and that the staff lacked professional knowledge. These might mean that the relationship becomes an I-It relationship where the older persons become an object, a relationship without devotion. In this kind of relationship, the conversation can be seen as a suit or a dress. The older person was accepted as one to be spoken to and there can be an interest, but the staff members did not give of themselves. In an I-It relation there is no time for experiences, the older persons are seen as an object, and there is no time for humour. ${ }^{[25]}$

However, the older persons could familiarize themselves with the staff's situation, that they were stressed and tired. The older persons received help by the staff and wanted, in return, to help them. The older persons used a collaborative manner; they were dependent on the staff and wished to have meaningful relationships with them. ${ }^{[33]}$ Human beings are interdependent rather than independent; we all rely on others as humans to have a good quality of life. ${ }^{[34]}$ In this study the older persons described that the staff were kind to them, and they were also in return kind to the staff. Humour 
was also used, so that the encounter and the atmosphere became positive. Reciprocity appears to be a prerequisite for building a relationship and collaboration. ${ }^{[9]}$ Reciprocity has been described as the give and take between individuals ${ }^{[35]}$ a kind of partnership in which both parts work together. ${ }^{[36]}$ When both the caregiver and care recipients make an effort to let the other person help and accept, an equal relationship and reciprocal care strategies can be created. ${ }^{[9,10]}$ Grasser and $\mathrm{Craft}^{[35]}$ describe how older persons want to give something meaningful back because they appreciate what has been done for them, which seems crucial for a meaningful daily life.

Reciprocity appears to be a prerequisite for collaboration in the older person's home to create meaning. It is described as important for the collaboration between rehabilitation teams, where reciprocity underpinned the extent to which individuals shared information within teams. ${ }^{[37]}$ However, it is strange that the older person was not naturally seen as one of the team. An abundance of reports highlight the need for increased participation by older persons in their care. When and if the staff reports and documents the care performed on an older person without the older person being involved, it becomes an I-It relationship.

It is important that the staff members are aware of the relationship's significance and invites the older persons into a reciprocal relationship. Buber ${ }^{[25]}$ argues that a person exists in the anthropological sense only in relation to another person. Through reciprocity it can be possible to understand what it is to be human. One condition is that no one forces him/herself on the other.

\subsection{Relationship between the older person and the staff}

An opportunity and a solution to develop a meaningful daily life was a relationship between the older person and the staff. It was clear that the older people wanted to have a close relationship with the staff for a meaningful daily life; their engagement was described as love. Several studies describe the relationship between the staff and the older person, including emotional ties that can be described as friendship ${ }^{[9]}$ or used family analogies as "my own daughter". ${ }^{[10]}$ When the older person was able to offer their friendship in exchange for aid and appreciation, they experienced a positive relationship, while the absence of reciprocity was perceived as isolating and alienating. ${ }^{[9]}$ McGarry's ${ }^{[10]}$ study showed that the relational aspects in home care were very important both for the older person and the staff. Important to keep in mind is that this can be individual; there are older persons who do not want a close relationship with the staff. $^{[36]}$ However, a relationship constituted by an I-Thou relation means that the self as a person, with all that this entails, continues to exist with its integrity and degree of private sphere. ${ }^{[24]}$
Health care professionals might view the older persons as frail. There may be a difference between a staff member who determines that someone is frail, ${ }^{[38]}$ which can be done if the staff member sees the older person as an object in an I-It relationship. ${ }^{[24]}$ This will make the older person feel frail. ${ }^{[38]}$ In an I-Thou relationship, ${ }^{[24]}$ the staff member shares the older person's emotional experiences ${ }^{[38]}$ and sees the older person as a subject and not someone that is frail. Thus, the older person will not feel frail. WHO means that if one only looks at older persons as helpless and frail, this creates stereotypical conceptions and ageism. ${ }^{[1]}$ If someone is looked upon as frail, his or her experiences and knowledge will not be asked for by the staff, who then will then decide what is best for the older person, which results in an I-It relation. ${ }^{[24]}$

The dialogue between the older person and the staff was an opportunity and a solution for a meaningful day, which was important for their relationship. A dialogue of a mental togetherness is the foundation of the relationship. ${ }^{[9]}$ To continue in the dialogue where they last ended was the "glue" that tied together their relationship and the everyday life. Together they could share experiences and continue to talk about them, when they met the next time. When two persons have a dialogue, this entails what is going on in the other's soul. In a dialogue, it's about seeing the other as a unique human being. ${ }^{[25]}$ However, for the dialogue to be genuine or authentic, each participant must contribute with him/herself. The authentic dialogue is based on a trust in each other. A true dialogue cannot be allocated in advance; many persons discover what they have to say on the spur of the moment. ${ }^{[25]}$ An authentic dialogue must be performed without hierarchy.

\subsection{Sense of belonging}

Another opportunity to develop a meaningful daily life was to have a sense of belonging to others and the family. Obstacles to this were if there was no room for the soul in the everyday life and if the older person felt alone. As we age our sense of significance is threatened, as we experience multiple losses. ${ }^{[39]}$ In addition, older persons can have several chronic diseases, ${ }^{[40]}$ which can affect their life situation where existential thoughts are raised. Older persons can no longer trust their own bodies, which are not as mobile as before. Life shrinks both physically, mentally and socially, where they can be trapped in their home. ${ }^{[41]}$ To lack close relationships can lead to alienation, where loneliness can lead to negative memories and thoughts. ${ }^{[42]}$ The sense of belonging may have a protective role against loneliness in older adults living at home. ${ }^{[43]}$

The older persons in this study often watched television and this viewing might alleviate loneliness and give a sense of belonging. ${ }^{[11]}$ It can be a link to the outside world through the provision of information of what is happening in the society $^{[44]}$ and give a sense of still belonging to and being a 
part of the society. There may also be an opportunity to calmly sit down, think and reflect. ${ }^{[45]}$ For the older persons in this study, the relationship and togetherness with family and friends were opportunities for a meaningful daily life. Even in other studies, the family's role is revealed as creating meaning in everyday life. ${ }^{[4]}$ Engagement in the family, mainly children and grandchildren, can structure and control everyday life for the older person, instead of the older person focusing on illness and disability. ${ }^{[47]}$

It is important to have a sense of belonging: to feel a "part of things", to be able to maintain existing relationships and to form new ones. A way to support the older person is to support them in keeping contact with family and friends that can live far away through technologies such as skype. ${ }^{[39]}$ Another way for the staff to support the older person's sense of belonging and continuity is to recognize and value the older person's life biography. ${ }^{[39]}$ The older person might need to tie the past with the present, to experience a future. ${ }^{[48]}$

Therefore, creating an environment in which older people feel that they really "matter" is crucial. ${ }^{[39]}$ In this study the older persons stressed the significance of the staff's engagement; a hug could give intimacy and warmth. The touch from a staff member can be the only touch an older person without a family or friends has, and this may be a way to confirm the other person. Buber talks about confirmation as one of the most basic human needs. The interpersonal extends beyond sympathy's limits, where other persons will be met as a partner in a life-course of events. ${ }^{[25]}$ This I-Thou relation can be interpreted as a room for the soul in a shared everyday life.

\subsection{Method discussion}

In action research it is important that the participants take part as co-researchers. ${ }^{[49]}$ In the present study, the older persons can be seen as co-researchers in the collection of data. Thus, they were able to change, delete or advise shortcomings as well as add to the data. However, the role of the researcher may be to draw conclusions from the research data, ${ }^{[50]}$ for example, interpret what the older person has said out of Buber. However, the research was also associated with some difficulties. Some of the older persons could have difficulties to keep in mind what had been said in the first interview. To handle this, the researchers saw it as important that the time between the interviews was not too long due to the risk that the participants had forgotten the prior conversations. The older persons were positive to participate in the research. The repeated interviews and going back several times to conduct reflections have deepened the knowledge

\section{References}

[1] World Health Organisation. Are You Ready? What You Need to Know About Ageing. 2013. Available from: of a meaningful daily life of older persons living in ordinary housing with home care. This can be seen as a form of validation, ${ }^{[51]}$ i.e., strength in the study. During the interpretation process we tried to maintain an open attitude ${ }^{[52]}$ and be open to the text. To strengthen the trustworthiness, we critically tested other possible theoretical interpretations. However, from our perspective, the main interpretation in this study, using Buber's philosophy of dialogue, best explains the results. ${ }^{[52]}$

\section{Conclusion}

A meaningful daily life for the older person was seen in the relationship to oneself, to the staff, to others and to the family. It was the ongoing conversation between the older person and the staff who became "the glue" and formed the relationship. The staff needed to support the older persons, maintaining their habits and routines in everyday life in order to create a meaningful daily life. Further, they needed to pay attention to the older persons' own resources and allow them to create reciprocity. The staff needed engagement by inviting the older person into a relationship. The sense of belonging was crucial for the older person to alleviate the feeling of loneliness. To help the older person with keeping in touch with family and to paying attention to their life story can provide support for the sense of belonging in a shared everyday life. A meaningful daily life can be obtained in an I-Thou relation in a shared everyday life, There the relationship and the continuing dialogue becomes the power of balance. The relationship is also relevant for the staff and, in line with Buber's thoughts, on how we are shaped by humans in the encounter with others. This means that both the staff and the old person shape each other; we become human in our meetings by sharing everyday life together.

\section{Acknowledgements}

Authors' contributions: AK, KB, IJ designed the study. IJ made the initial analysis of the interview transcripts. Each step of the analysis was then scrutinized and discussed by AK, KB, IJ. Further, AK, KB, IJ made critical revisions to the manuscript and all the authors read and approved the final manuscript. We thank all the older persons who participated and shared their experiences and knowledge with us. Further, we also thank the research assistants who so carefully conducted interviews with the older persons. Funding has been gratefully received from the Örebro University.

\section{Conflicts of Interest Disclosure}

The authors declare no conflicts of interest. http://www.who.int/world-health-day/2012/toolki t/background/en/201301106

[2] Australian Institute of Health and Welfare: Aged Care Packages in the Community 2006-07: A Statistical Overview. In Aged Care Statistics Series. Volume 27. Canberra: Australian Institute of 
Health and Welfare; 2008.

[3] World Health Organisation. Global Health and Aging. National Institute on Aging, National Institutes of Health, U.S Department of Health and Human Services. 2011. Available from: http://www . who.int/ageing/publications/global_health.pdf

[4] Low 1-F, Yap M, Brodaty H. A Systematic Review of Different Models of Home and Community Care Services for Older Persons. BMC Health Services Research. 2011; 11(93), 1-15. http: //dx.doi.org/10.1186/1472-6963-11-93

[5] Genet N, Boermal WG, Kringos DS, et al. Home Care in Europe: A Systematic Literature Review. BMC Health Services Research. 2011; 11: 207. http://dx.doi.org/10.1186/1472-6 963-11-207

[6] Twigg J. The Body in Health and Social Care. Basingstoke: Palgrave Macmillan; 2006.

[7] Clarfield AM, Bergman H, Kane R. Fragmentation of Care for Frail Older People; An International Problem. Experience from Three Countries: Israel, Canada, and the United States. Journal of American Geriatric Society. 2001; 49(12): 1714-1721. PMid:11844008. http://dx.doi.org/10.1046/j.1532-5415.2001.49285.x

[8] Andersson K. Omsorg under förhandling: Om tid behov och kön i en föränderlig hemtjänstverksamhet. (Care during the Negotiation: If Time Needs and Gender in a Changing Assisted Living Activities). PhD Thesis, Umeå University, Institution for Social Work. 2007.

[9] Gantert TW, McWilliam CL, Ward-Griffin C, et al. The Key to Me: Seniors' Perceptions of Relationship-building with In-home Service Providers. Canadian Journal on Aging. 2008; 27(1): 23-34. http://dx.doi.org/10.3138/cja.27.1.23

[10] McGarry J. Defining Roles, Relationships, Boundaries and Participation between Elderly People and Nurses Within the Home: An Ethnographic Study. Health and Social Care in the Community. 2008; 17(1): 83-91. http://dx.doi.org/10.1111/j.1365-2 $524.2008 .00802 . \mathrm{x}$

[11] Birkeland A, Natvig GK. Coping with Ageing and Failing Health: A Qualitative Study among Ederly Living Alone. International Journal of Nursing Practice. 2009; 15: 257-264.

[12] Sanders S, Polgar JM, Kloseck M, et al. Homebound Older Individuals Living in the Community: A Pilot Study. Physical \& Occupational Therapy in Geriatrics. 2005; 23(2/3): 145-160.

[13] Socialdepartementet: Lagrådsremiss: Värdigt liv i äldreomsorgen. The Council of Legislation Remittance: Dignity Life in Elderly Care. Stockholm: Socialdepartementet [Swedish Ministry of Health and Social Affairs] (In Swedish); 2010. Available from: http: //ww w.regeringen. se/content/1/c6/13/82/85/361b7b6b.pdf

[14] Harnett T. The Trivial Matters: Everyday Power in Swedish Elder Care. PhD Thesis. Jönköping University, School of Health Sciences Sweden; 2010.

[15] Teeri S, Välimäki M, Katajisto J, et al. Scandinavian Journal of Caring Science. 2007 Dec; 21(4): 490-9. PMid:18036012. http: //dx.doi.org/10.1111/j.1471-6712.2007.00499.x

[16] Haugan G. Meaning-In-life in Nursing-home Patients: A Correlate with Physical and Emotional Symptoms. Journal of Clinical Nursing. 2013; 23: 1030-1043. PMid:24350911. http://dx.doi.org /10.1111/jocn. 12282

[17] James I, Blomberg K, Liljekvist E, et al. Working Together for a Meaningful Daily Life for Older Persons: A Participatory and Appreciative Action and Reflection Project-The Lessons We Have Learned.

[18] Ghaye T, Melander Wikman A, Kisare M, et al. Participatory and Appreciative Action and Reflection (PAAR) Democratizing Reflective Practices. Reflective Practice. 2008; 9(4): 361-397. http: //dx.doi.org/10.1080/14623940802475827

[19] Patton M.Q. Qualitative Research \& Evaluation Methods. 3rd Ed. London UK: Sage; 2002.

[20] Örebro Municipality. Influence and Participation in Nursing Homes and Home Care. 2010. Örebro, Sweden: Social Welfare Örebro Municipality. Available from: http://www.orebro.se/downlo ad/18.47c6f44f12dd9e9713780002115/1392724621772/S\% C3\%A4rskilda+boenden $+\mathrm{f} \% \mathrm{C} 3 \% \mathrm{~B} 6 \mathrm{r}+\% \mathrm{C} 3 \% \mathrm{~A} 4 \mathrm{ld}$ re $\% 2 \mathrm{C}+$ derast anh $\%$ C3\%B6riga+och themv\%C3\%A5rden+helatunders $\%$ C3\%B6 kningen+-+brukarunders\%C3\%B6kning+2010.pdf

[21] Kvale S, Brinkmann S. Interviews: Learning the Craft of Qualitative Research Interviewing. 2nd Ed. Los Angeles: Sage Publications; 2009.

[22] Thorne S. Interpretive Description. Walnut Creek, CA: Left Coast Press; 2008

[23] Lincoln YS, Guba EG. Naturalistic Inquiry. London: Sage Publication Inc; 1985.

[24] Buber M. The Interpersonal. (2nd Ed.) Ludvika: Dualis; 1995.

[25] Buber M. I and Thou. New York: Charles Scribner's Sons; 1970.

[26] Avlund K, Lund R, Holstein B, et al. Social Relations as Determinant of Onset of Disability in Aging. Archives of Gerontology and Geriatrics. 2004; 38: 85-99. PMid:14599708. http://dx.doi.o $\mathrm{rg} / 10.1016 / \mathrm{j}$. archger . 2003.08.003

[27] Hammarström G, Torres S. Being, feeling and acting: A qualitative study of Swedish home-help care recipients' understandings of dependence and independence. Journal of Aging Studies. 24 (2010): 75-87. http://dx.doi.org/10.1016/j.jaging. 2008 .10 .002

[28] Dollard J, Barton C, Newbury J, et al. Falls in Old Age: A Threat to Identity. Journal of Clinical Nursing. 21: 2617-2625.

[29] Goffman E. The presentation of self in everyday life. London: Penguin; 1990

[30] Cristoforetti A, Gennai F, Rodeschini G. Home Sweet Home: The Emotional Construction of Places. Journal of Aging Studies. 2011; 25(3): 225-232. http://dx.doi.org/10.1016/j.jaging. 20 11.03 .006

[31] James I, Sjöman L, Blomberg K, et al. A Meaningful Daily Life in Elderly Care?: A Literature Review (In Swedish). Kumla: Inger James; 2013.

[32] Giddens A. Modernity and Self-identity: Self and Society in the Late Modern Age. Cambridge: Polity Press; 1991.

[33] Small JA, Montoro Rodriguez J. Conflict Resolution Styles: A Comparison of Assisted Living and Nursing Home Facilities. Journal of Gerontological Nursing. 2006; 32(1): 39-45. Available from: http: //europepmc.org/abstract/MED/16475464 PMid:16475464.

[34] Reed J, McCormack B. Independence and Autonomy - The Foundation of Care Jan Reed and Brendan McCormack. The Aims and Goals of Care: A Framework Promoting Partnerships between Older People, Family Carers and Nurses. In J. Reed, C. Clarke, and A. Macfarlane (Eds.), Nursing Older Adults. Berkshire, GBR: Open University Press; 2011. 9-23p

[35] Grasser SC, Craft BJ. The Blessing of Giving: The Importance of Reciprocity to Self-Health Care. Geriatric Nursing. 2000; 21(3): 138-143. PMid:10864693. http://dx.doi.org/10.1067 /mgn. 2000.108258

[36] McGilton KS, Boscart VM. Close Care Provider-Resident Relationships in Long-term Care Environments. Journal of Clinical Nursing. 2007; 16: 2149-2157.

[37] Croker A, Trede F, Higgs J. Collaboration: What Is It Like? Phenomenological Interpretation of the Experience of Collaborating Within Rehabilitation Teams. Journal of Interprofessional Care. 2012; 26: 13-20. PMid:22233363. http://dx.doi.org/10.3109 $/ 13561820.2011 .623802$

[38] Grenier A. The Distinction between Being and Feeling Frail: Exploring Emotional Experiences in Health and Social Care. Journal of Social Work. 2006; 20(3): 299-313. http://dx.doi .org/10. 1080/02650530600931849

[39] Nolan M, Allan S, McGeever P, et al. The Aims and Goals of Care: A Framework Promoting Partnerships between Older People, Family Carers and Nurses. In J. Reed, C. Clarke, \& A. Macfarlane (Eds.), Nursing Older Adults. Berkshire, GBR: Open University Press; 2011. 23-43p.

[40] World Health Organisation. Ageing and Life Course. Interesting Facts about Ageing. 2012, March 28. Available from: http://ww w. who.int/ageing/about/facts/en/

[41] Zidén L, Wenestam C-G, Hansson-Scherman M. A Life-breaking Event: Early Experiences of the Consequences of a Hip Fracture for Elderly People. Clinical Rehabilitation. 2008; 22: 801- 
811. PMid:18728133. http://dx.doi.org/10.1177/0269215 508090204

[42] From I. Experiences of Health and Care When being Old and Dependent on Community Care. Licentiate Dissertation, Karlstad University. Faculty of Social and Life Sciences, Department of Nursing; 2007.

[43] Maria Eugenia Prieto Flores M-E, Gloria Fernandez Mayoralas G, Forjaz M J, et al. Residential Satisfaction, Sense of Belonging and Loneliness among Older Adults Living in the Community and in Care Facilities. Health \& Place. 2011; 17: 11831190. PMid:21924944. http://dx.doi.org/10.1016/j.healt hplace.2011.08.012

[44] De Witt L, Ploeg J, Black M. Living on the Threshold. The Spatial Experience of Living Alone with Dementia. Dementia. 2009; 8(2): 263-291. http://dx.doi.org/10.1177/1471301209103273

[45] Östlund B. Watching Television in Later Life: A Deeper Understanding of TV Viewing in the Homes of Old People and in Geriatric Care Contexts. Scandinavian Journal of Caring Sciences. 2009; 24(2): 233-243.

[46] Dwyer L-L, Nordenfelt L, Ternersted B M. Three Nursing Home Residents Speak about Meaning at the End of Life. Nursing Ethics.
2008; 15(1): 97-109. http://dx.doi.org/10.1177/0969733 007083938

[47] Vik K, Nygård L, Borell L, et al. Agency and Engagement: Older Adults' Experiences of Participation in Occupation during Homebased Rehabilitation. Canadian Journal of Occupational Therapy. 2008; 75(5): 262-271. http://dx.doi.org/10.1177/0008417 40807500504

[48] Ricoeur P. Time and Narrative: Volume 3. Chicago: University of Chicago Press; 1998.

[49] Bradbury Huang H. What is Good Action Research? Why the Resurgent Interest? Action Research. 2010; 8(1): 93-109. http: //dx.doi.org/10.1177/1476750310362435

[50] Wermeling E, Nydahl E. From Research Object to Co-actor: About Collaboration between Researchers and Those that the Research Concerns (in Swedish). Sundbyberg: Handikappförbunden; 2011.

[51] Adili F, Higgins I, Koch T. Older Women and Chronic Illness: Transitioning and Learning to Live with Diabetes. Action Research. 2013; 11(2): 142-156. http://dx.doi.org/10.1177/1476750 313477157

[52] Dahlberg K, Dahlberg H, Nyström M. Reflective Life World Research. Lund: Studentlitteratur; 2008. 